\title{
Ten health stories that mattered Feb. 3-7
}

- Access to sufficient, healthy food is worsening across the country, according to a report, Household Food Insecurity in Canada. Since 2011, the number of Canadians living in food insecure households has increased by 130000 , bringing the national total to over 4 million people, or almost $13 \%$ of households.

- Certain types of blood pressure medications should not be taken in combination, Health Canada said in a notice to doctors and patients. Any combination of aliskiren, angiotensin-converting enzyme inhibitors, or angiotensin receptor blockers increases the risks of low blood pressure, high levels of potassium in the blood and kidney problems, warned the regulator.

- A study by researchers at the University of Toronto in Ontario, suggests environmental reviews of oil sands operations in Alberta have probably underestimated health risks. Assessments did not factor in all sources of potentially hazardous air pollution, including evaporation from tailings ponds and dust from mining sites.

- Health Canada is urging doctors to consider checking patients' calcium blood levels before prescribing lithium, a psychiatric drug widely used in the treatment of bipolar disorder. According to a new advisory, the drug can cause hypercalcemia or high levels of calcium in the bloodstream, as well as the hormone disorder hyperparathyroidism.

- About 7 in 10 survivors of heart attack or stroke make healthy changes after their scare, but less than half can maintain those changes, according to a Heart and Stroke Foundation report. Part of the problem is that only about one-third of cardiac survivors and $19 \%$ of patients with stroke who are eligible for rehabilitation are referred to a program.

- A new breast cancer screening policy in British Columbia urges women aged 40 to 74 to have annual mammograms if a first-degree family member has been diagnosed with the disease. The BC Cancer Agency has also reduced the frequency at which women aged 40-49 may be screened without a doctor's referral from annually to once every two years.

- A British Columbia microbiologist is calling for a better alert system in Canadian hospitals for cases of CPE, or carbapenemase-producing enterobacteriaceae. Fraser Health Author- ity hospitals have intermittently found cases of the multidrug-resistant bacteria, and recently warned the public of an outbreak at the Royal Columbian Hospital in New Westminster.

- Alberta has pledged \$5 million to mental health services for vulnerable kids, which includes counselling for children the province removes from their parents. The new funds will also pay for crisis support on evenings and weekends by phone for foster parents and caregivers of vulnerable children.

- Unsafe drugs often remain on the market in Canada for more than three years before being pulled from pharmacy shelves, a new study in Open Medicine shows. Some drugs received a serious safety warning within 20 days of being approved by Health Canada, but the median time between approval and withdrawal was 1271 days.

- Cancer and heart disease remain the top two leading causes of death for both men and women, according to Statistics Canada. Together, these two causes of death were responsible for half of all deaths in Canada.Lauren Vogel, CMAJ

CMAJ 2014. DOI:10.1503/cmaj.109-4724 